\title{
THE PHONICS METHOD IN TEACHING EFL PRONUNCIATION TO YOUNG LEARNERS WITH DYSLEXIA
}

\author{
Zdena Kralova $^{1}$, Daniela Soradova ${ }^{2}$
}

\begin{abstract}
The Phonics method brings more logic into the correspondence between English pronunciation and spelling. Therefore, it might be beneficial for learners with special educational needs (namely dyslexia). The study investigates the effectiveness of the Phonics method in teaching English pronunciation to young non-native learners comparing the achievement of the intact and the integrated learners. The Phonics method was applied for five months in the experimental group, and other, more traditional methods for teaching EFL pronunciation were applied in the control group at an elementary school in Slovakia. Both groups consisted of the intact and the integrated learners (experimental group: 19 intact and 2 integrated learners; control group: 17 intact and 2 integrated learners). The learners underwent a dictation and a reading test in pre-test and post-test, and the results indicate the benefit of the Phonics method for all learners with significant improvement among learners with dyslexia. The integrated learners' improvement rate was nearly six times (dictation)/three times (reading test) higher in the experimental group than in the control group.
\end{abstract}

UDC Classification: 81.34, DOI: https://doi.org/10.12955/pss.v2.223

Keywords: English, pronunciation, Phonics, dyslexia, young learners.

\section{Introduction}

It is expected that for learners with even little problems in learning their mother tongue, learning the phonology of a foreign language may be a challenge. Most dyslexic learners speak more slowly in a foreign language, show insufficient phoneme discrimination and have problems in learning vocabulary due to the reduced capacity of short-term memory (Crombie, 1999). Working memory coordinates the phonological loop specializing in the manipulation and retention of speech (Gathercole, 1999). Limited working memory thus makes it harder for learners with dyslexia to process and manipulate sounds and transfer the information to long-term memory.

From the neurological and cognitive point of view, the Phonological Deficit Hypothesis explains that dyslexia is caused by impaired phonemic awareness working on the levels of segmental and plurisegmental knowledge. Plurisegmental knowledge includes the ability to divide words into syllables and manipulate them, whereas segmental knowledge involves the ability to segment words into sound elements and operate them. As a result, dyslexic learners often struggle with word processing (Kormos \& Smith, 2012). Learners with dyslexia have lower phonetic competence, which means they have trouble understanding the phonic form of words. They synthesize, analyze and even rhyme words with difficulties and therefore, to improve these skills, they need a special methodology of teaching (International Dyslexia Association, 2016). Therefore, Schneider and Crombie (2003) suggest foreign languages having regular letter-sound correspondence to be taught to dyslexic learners.

However, to achieve an adequate level, dyslexic learners need significant assistance from their teachers, who are supposed to look for the most appropriate techniques. Ganschow et al. (1998) recommend the Multisensory Structured Language (MSL) approach in such cases. Another choice could be the OrtonGillingham Approach (Kormos \& Smith, 2012), that is based on MSL, which teaches the graphemephoneme relationship explicitly and activates more senses simultaneously. This approach also provides several clues to help learners distinguish similar letters like $b$ and $d$ (International Dyslexia Association, 2016).

\section{Literature review}

English is a non-phonemic language, i.e. the way words sound does not always reflect their written form. Teaching and learning EFL (English as a foreign language) pronunciation is thus rather difficult, especially for speakers of phonemic languages with a systematic correspondence between letters and sounds (Kralova et al., 2020). In the English language, a grapheme can be pronounced in different ways, a grapheme cluster can be pronounced as one sound, or one phoneme is addressed by various graphemes.

\footnotetext{
${ }^{1}$ Constantine the Philosopher University in Nitra, Faculty of Education, Department of Language Pedagogy and Intercultural Studies; Tomas Bata University in Zlin, Faculty of Humanities, Department of Modern Languages and Literatures, zkralova@ukf.sk, ORCID: 0000-0001-6900-9992

${ }^{2}$ Constantine the Philosopher University in Nitra, Faculty of Education, Department of Language Pedagogy and Intercultural Studies, daniela.soradova@ukf.sk, ORCID: 0000-0002-8693-2241
} 
To learn this, the patterns must be logically structured, which is done so by the Phonics method (Burns et al., 1988).

Originally, Phonics was a method used to teach reading and writing to English native speakers. However, in the last years, it has reached EFL classrooms too. Phonics instructions teach the relationship between graphemes and phonemes and are divided into stages when individual letters or their letter combinations are taught to be read. It starts with simple words when one letter represents one sound and continues with more syllable words where one sound is represented by more letters or one letter represents more sounds (Reading Rockets, n.d.).

Phonics is a methodology based on sound-letter combinations learnt phonically (Scott \& Ytreberg, 1994, p. 49). Nevertheless, learners should be prepared for the use of Phonics. Phonemic awareness - the ability to discriminate sounds is a forerunner and an inevitable precondition for Phonics application (Hiskes, 2011). Incorporating Phonics is a move from simple comprehension toward extensional awareness, and students' metacognitive abilities thus expand (Brooks \& Brooks, 2005).

The Phonics method is divided into Synthetic and Analytic Phonics. Analytic Phonics uses a whole-topart approach and starts with the whole word, which is analyzed into segments. Then the graphemephoneme relations are studied. On the other hand, Synthetic Phonics is based on a part-to-whole approach and primarily focuses on letters related to sounds. They are later combined in order to pronounce the word. Nevertheless, it cannot yet be definitely stated which approach is more suitable for young non-native learners of English. In the end, it is up to governments, schools and teachers to make their choice on which approach should prevail in lessons. The United Kingdom government now recommends including Synthetic Phonics for early reading instructions based on the Rose Report by the Secretary of State for Education for England (Wyse \& Styles, 2007). Within the United Kingdom, each country may choose which approach they are going to base their early reading instructions on.

There is a number of commercial or certified Phonics methods such as Linguistic Phonics, Systematic Contextual Phonics, Embedded Phonics, or Jolly Phonics. They are either synthetically centered or analytically centered, and some are applied to first language learners, while some of them are more suitable for foreign language learners. Linguistic Phonics based on Synthetic Phonics is one of the most frequently used programs at schools. Its aim is to help learners understand the correspondence between the spoken and written form of words. Listening comprehension and speaking skills are emphasized. Compared to other Phonics methods, Linguistic Phonics reduces memorization and enhances interaction with the material. Classifications and rules are not explicitly taught, and learning is performed within a meaningful context: sounds in words and words in texts (Linguistic Phonics, 2009).

Although the rules are not directly explained to learners due to the phonological skills (sound segmenting and blending, phoneme manipulation) that are applied in the lessons. Learners thus realize that there is a different number of letters compared to sounds or that they can cut up words into smaller chunks (Linguistic Phonics, 2009). To develop phonological skills towards automaticity, learners should be offered a scale of multisensory activities, e.g. word formation, word creation and sentence building. The program of Linguistic Phonics lasts about two years, and it is suited to learners of English as a first language because the previously acquired vocabulary facilitates working with Linguistic Phonics. Vocabulary is the crucial thing that is often missed by second and foreign language learners, and therefore, Linguistic Phonics would not be completely appropriate for them. Although it is recommended to use Synthetic Phonics as a basic methodology of teaching reading to all learners and supplement it with Analytical Phonics (Learning Village, 2016), there is still the absence of literature and research supporting the worth of Synthetic Phonics by foreign language learners (Birch, 2002; Nuttal, 1996).

Most of the studies discussing teaching Phonics come from the environment where the first language is learnt. McArthur et al. (2012) measured the impact of Phonics application on language skills of Englishspeaking young and adult learners, whose reading comprehension was one grade below the expected level. They concluded that the Phonics method proved to improve non-word reading accuracy largely, word reading accuracy moderately, and grapheme-phoneme association less significantly. Three years later, another study by the same author was published comparing The Whole Word training and Phonics in different orders and concluded that Phonics before The Whole Word training had a slight advantage over the introduction of The Whole Word first (McArthur et al., 2015). 
There are also some commercial Phonics programs with their own copyright, materials, lecturers and attractive web applications with tutorials and testimonials. For example, the Barton Reading \& Spelling System (Barton, 2016), operating since 1998, is a research-based teaching program for young to adult learners with special educational needs. The Wilson Language Training program (2016), certified by the International Dyslexia Association, is a structured program based on the Orton-Gillingham principles (Gillingham \& Stillman, 1960) teaching encoding and decoding language skills.

Nevertheless, to the best of the authors' knowledge, there are only a few studies analyzing Phonics effectiveness among foreign language learners with special educational needs. Ahmad et al. (2012) utilized the Phonics Reading Technique and the Multisensory Approach in combination with interactive multimedia for Malay dyslexic learners. They stated that using a mix of the approaches was more intriguing, appealing and easier for the participants than traditional teaching techniques.

The primary objective of the current research was to find out the effectiveness of the Phonics method in teaching English pronunciation to young non-native speakers with the focus on dyslexic learners. We thus investigated the impact of the Phonic method as an adapted additional approach in inclusive classes at a Slovak primary school on the improvement of learners' English pronunciation. Slovak pupils generally start to read and write in English in year three, that is, after they have already learnt how to read and write in Slovak. Therefore, they do not have to start with the whole alphabet all over again in English, but they often struggle, as they learn the pronunciation and spelling of English words by heart, and they do not see the connections between the written and spoken form straight away. Therefore, we believe that Phonics in its adapted synthetic form, mostly taught by The Whole Word approach, is beneficial for learners with specific learning differences who require regularities, straightforward and clear instructions (Kovacikova, 2016).

\section{Data and methodology}

Sample

The non-probability sampling - purposive sample was applied in the action research conducted in the experimental and the control group of young learners (11-12 years of age). There were 19 intact and 2 integrated learners with dyslexia in the experimental group and 17 intact learners and 2 integrated learners with dyslexia in the control group.

\section{Procedure}

Within the experiment, an identical form of dictation and reading test was applied as pre-test and posttest in both groups. The intervention (Phonics instructions) was introduced only in the experimental group once a week for five months. The control group followed identical lesson plans applying other, more traditional, methods for teaching EFL pronunciation - drills, repetition, songs, rhymes, reading aloud, minimal pairs and tongue twisters (Kralova, Soradova, \& Birova, 2018). Both groups were taught by the same teacher (one of the authors).

\section{Instruments}

\section{Dictation}

The dictation was composed of words that were known to learners, but also the words that were going to be covered later during the intervention (knees, hear, plant, bunny, tree, hill, mall, with, Kathy, technology, heads, mum, can, make, cake, stream, catch, fish, wish, nice, call). An error rate before and after the intervention and the improvement rate were detected in both groups. The error rate was calculated as the ratio of the number of mistakes and the number of learners. The improvement rate was calculated as the difference between the error rates in pre-test and post-test.

\section{Reading test}

The reading test was also composed of familiar or covered words (hi, name, Kathy, know, school, leave, home, like, bun, with, cup, tea, chocolate, cake, coffee, puppy, all, football, bike, can, jump, run, wall, classroom, book, chair, time, please, she, Shelly, agree, shark, sharp, teeth). An error rate before and after the intervention and the improvement rate were detected in both groups.

\section{Intervention}

The Phonics method applied presented all the sounds in a prescribed manner because the learners' knowledge of English and their vocabulary did not require the introduction of individual vowels or consonants. The participating learners had been studying English for at least five years, so the range of 
their vocabulary was helpful in introducing Phonics instructions. They were able to come up with their own examples to create "families" of the same sound. The graphemes that tend to cause problems to Slovak learners because of native language interference were selected (Kralova, Nemcokova \& Birova, 2020): $a$ as in cat; ar as in car; al as in ball; sh as in fish; ch as in chin or school; th as in thin or father; $e e$ as in week; ea as in mean; $n g$ as in sing; $w r$ as in wrap; $k n$ as in knee; and final $e$ changing the preceding vowel as in cake.

Identical lesson plans were used in both groups, but a short reading practice followed by the Phonics instructions was introduced in the experimental group only to point out the Phonics rules and practice pronunciation. The exercises were formed so that learners could see how the sounds are represented in a written form with a number of examples. The teacher also reacted to mispronunciations that occurred during the lessons and tried to incorporate the phonological skills and make learners realize and correct their mispronunciations. In some fill-in exercises, learners were supposed to write the correct sounds based on the way they read them. The words they know were combined with the unknown ones or even the exceptions to encourage guessing the right pronunciation. Learners did not only fill in the exercises, but every time they also practiced pronunciation by reading either the texts or words. There were also exercises that required more critical thinking from the learners. Although there was often a rule, the deductive approach was applied where they had to divide the words according to how they are pronounced and deduce the rule themselves.

Learners were often working in pairs or in groups. Intact learners were mingled with the integrated ones so that they could help each other. In some activities, learners were also rewarded with sweets or other little rewards, which was very popular and motivating for them. A very popular game among learners was slapping a word written on the board with a fly swatter. Learners were randomly divided into two even groups and in each group there was also an integrated learner. The words written on the board contained minimal pairs that are written similarly but pronounced differently. The teacher said the word and the learner who found the correct word written on the board according to what they heard slapped it and moved to the back of the line. The group where everybody answered correctly won.

Final, the - $e$ influence on the pronunciation of a previous vowel was explained. First, the vowels of the alphabet were revised, then their different pronunciation in some words was explained, such as $a$ as in can, $i$ as in spin, $u$ as in $c u b$ and then 'the magic $-e$ ' that changes the sound of the previous vowel as in can-cane, spin-spine, cub-cube was introduced. The cases where it cannot be applied were also pointed out. The Phonics method was also applied during the reading or written exercises when the learners were asked to correct themselves by giving them examples that contained the same sounds with familiar pronunciation or spelling. Then the word was segmented into individual sounds. The learners then looked for the same sound and blended the word together, deducing the correct pronunciation or spelling.

\section{Results and discussion}

\section{Experiment}

Dictation

The error rate was comparable in both groups in the pre-test (Table 1). All learners improved after the experiment. The intact learners' improvement rate in the experimental group was higher than in the control group by $0.67 \%$. Regarding the integrated learners, their error rate was much higher than the rate of intact learners both in pre-test and post-test. However, their improvement rate within the experimental group was nearly six times higher than in the control group, which is statistically significant at $\alpha=0.05(Z=5.398, p=0.000)$, while in the case of the intact learners, the improvement was similar in both groups $(Z=1.159, p=0.251)$.

In both groups, the error rate in the post-test was lower or remained the same in most of the tested words. Compared to the intact learners, the integrated learners had a higher tendency to use Slovak punctuation, such as nis (knees) or tri (tree), or they left out the words or even parts of the sentences.

Reading test

Similarly, the error rate in both groups was comparable in the pre-test (Table 2). The intact learners' improvement rate was nearly four times higher in the experimental group $(Z=4.803, p=0.000)$ and in 
the case of the integrated learners, three times higher than in the control group $(Z=2.327, p=0.020)$, which is statistically significant at $\alpha=0.05$.

\begin{tabular}{|l|l|r|r|r|r|}
\hline \multicolumn{2}{|l|}{ Table 1: Dictation results (\%) } \\
\hline & \multicolumn{2}{|c|}{ Pre-test } & \multicolumn{2}{|c|}{ Post-test } \\
\hline & & $\begin{array}{r}\text { Experimental } \\
\text { group }\end{array}$ & $\begin{array}{r}\text { Control } \\
\text { group }\end{array}$ & $\begin{array}{r}\text { Experimental } \\
\text { group }\end{array}$ & $\begin{array}{r}\text { Control } \\
\text { group }\end{array}$ \\
\hline \multirow{3}{*}{ Intact learners } & Error rate & 22.11 & 29.60 & 17.69 & 25.85 \\
\cline { 2 - 6 } & $\begin{array}{l}\text { Improvement } \\
\text { rate }\end{array}$ & - & - & 4.42 & 3.75 \\
\hline $\begin{array}{l}\text { Integrated } \\
\text { learners }\end{array}$ & Error rate & 61.91 & 69.85 & 52.38 & 68.25 \\
\cline { 2 - 6 } & $\begin{array}{l}\text { Improvement } \\
\text { rate }\end{array}$ & - & - & 9.53 & 1.60 \\
\hline
\end{tabular}

Source: Authors

Table 1: Reading test results (\%)

\begin{tabular}{|l|l|r|r|r|r|}
\hline & & \multicolumn{2}{|c|}{ Pre-test } & \multicolumn{2}{|c|}{ Post-test } \\
\hline \multirow{2}{*}{ Intact learners } & & $\begin{array}{r}\text { Experimental } \\
\text { group }\end{array}$ & $\begin{array}{r}\text { Control } \\
\text { group }\end{array}$ & $\begin{array}{r}\text { Experimental } \\
\text { group }\end{array}$ & $\begin{array}{r}\text { Control } \\
\text { group }\end{array}$ \\
\cline { 2 - 6 } & $\begin{array}{l}\text { Error rate } \\
\text { Improvement }\end{array}$ & 10.19 & 9.03 & 5.88 & 8.01 \\
\hline $\begin{array}{l}\text { Integrated } \\
\text { learners }\end{array}$ & Error rate & - & - & 28.43 & 1.13 \\
\cline { 2 - 6 } & $\begin{array}{l}\text { Improvement } \\
\text { rate }\end{array}$ & 31.37 & 32.35 & 2.94 & 0.00 \\
\hline
\end{tabular}

Source: Authors

No improvement rate was detected in the control group of integrated learners. Although the number of errors remained the same, different words were mispronounced in the post-test compared to their zero error rate in the pre-test.

There were no problems in applying phonological skills observed in the lessons. Learners understood very quickly what to do and corrected themselves. Mostly, they came up with other examples. After a short practice, they were able to cut the word into individual sounds or even substitute a certain sound if asked and to create a new word. When practicing phonological skills of segmenting, blending and phoneme manipulation, their vocabulary range was really helpful. In the experimental group, Phonics instructions were practiced intentionally by giving learners extra activities and incorporating them into regular exercises. By doing so, it was possible to follow an identical curriculum in both groups, combine new vocabulary, cover a new topic and practice pronunciation at the same time.

It can be stated that giving learners as many examples as possible helped them see the pattern. Consequently, they understood the rule and were able to apply it in exercises. When learners mispronounced the word even after the rule had been already introduced, it was sufficient just to give them similar examples, and they were able to correct themselves straightway. For example, when a learner mispronounced the sound $c h$ in the word school, it was pointed out that there is no $/ x /$ sound in English and other words like chair, Christmas were written on the board and ch was underlined. However, they had already known the word, so the self-correction was really quick.

Sometimes, learners mispronounced the words because they focused on pronouncing each individual letter as it is in their native language. After a little hint, they were able to correct themselves straightway. In the case of mispronouncing the word knee with the initial sound $/ k /$, it was only reminded that $k-n$ "do not like each other" and a learner corrected themselves, or somebody else shouted out the right pronunciation. The aim was to let learners correct themselves rather than correct them straightway and interrupt their reading. This way, they were thinking about the pattern, realizing or even deducing the rule. Phonics exercises were accommodated to the needs of the integrated learners, i.e. the font, the spacing, the color of the paper, etc. Learners were mostly working in pairs or groups in order to help each other. They were mingled differently and not just the way they would normally choose to so that the integrated learners would work with learners of different English levels. 


\section{Conclusion}

Practicing pronunciation is basically hidden in many exercises, like reading aloud or in any speaking activity. On the one hand, it is all right, but on the other hand, the whole process happens almost unconsciously without realizing certain facts. Therefore, the research was devoted to practicing English pronunciation on a conscious level and studying learners' conduct while applying the Phonics method.

Although the Phonics method is predominantly applied among native English speakers, the non-native learners were able to understand the phonetic rules, and hence they were soon able to apply the phonological skills to self-correct their pronunciation and engage their metacognitive skills by working with pronunciation on a conscious level. It was surprising how quickly the learners were able to react and come up with similar sound examples. What is more, the MSL approach was applied by using visuals and other mnemonic aids to engage more senses of the learners.

The results of the experiment show that the experimental group where intervention was applied improved more both in the dictation and the reading test compared to the control group. In the case of the integrated learners, the improvement was even more significant, indicating the benefits of the Phonics method in teaching English pronunciation, reading and spelling to non-native learners with special educational needs. According to the Phonics method, learners are allowed to guess pronunciation or spelling because it reflects the way they think about the language. However, in general practice, teachers often correct learners' pronunciation straightaway and consequently, there is no place for learners to realize that there are patterns that can be followed. What is more, when learners put more effort into deducing the rule or are given more examples, they process the language on a cognitive level. It can be stated that time was the biggest limitation in the current research. On the one hand, it would be ideal if a regular teacher incorporated the Phonics instructions into each lesson for a longer period of time. On the other hand, the integrated learners needed more time, more chances to go back to previously done exercises, more time to carry them out and more guidance from the teacher compared to the intact learners. Albeit there is no place to educate each child individually in most schools, there should be a place to accommodate teaching in order to fit the individual needs of learners.

\section{Acknowledgements}

This work was supported by the Cultural and Educational Grant Agency of the Ministry of Education, Science, Research and Sport of the Slovak Republic (KEGA 002UKF-4/2020).

\section{References}

Ahmad, S. Z., Ludin, N. N. A. N., Ekhsan, H. M., Rosmani, A. F., \& Ismail, M. H. (2012). Applying Phonic reading technique and multisensory approach with interactive multimedia for dyslexia children. In IEEE Colloquium on Humanities, Science and Engineering (pp. 554-559). Sabah: Kota Kinabalu. doi:10.1109/CHUSER.2012.6504375

Barton, S. (2016). Barton reading and spelling system. Retrieved from https://bartonreading.com/

Birch, B. M. (2002). English L2 reading: Getting to the bottom (ESL \& Applied Linguistics Professional Series) (1 ${ }^{\text {st }}$ ed.). Routledge.

Brooks, M. C., \& Brooks, J. S. (2005). Whole language or Phonics: Improving language instruction through general. Et Cetera, 62(3), 271-280.

Burns, P. C., Roe, B. D., \& Ross, E. P. (1988). Teaching reading in today’s elementary schools. Boston: Houghton Mifflin.

Crombie, M. (1999). Foreign language learning and dyslexia. Retrieved from

http://www.hilarymccoll.co.uk/resources/Dxa1.pdf

Ganschow, L., Sparks, R., \& Javorsky, J. (1998). Foreign language learning difficulties. Journal of Learning Disabilities, 31(3), 248-258. https://doi.org/10.1177/002221949803100304

Gathercole, S. E. (1999). Cognitive approaches to the development of short-term memory. Trends in Cognitive Sciences, 3(11), 410-419. https://doi.org/10.1016/s1364-6613(99)01388-1

Gillingham, B., \& Stillman, B. (1960). Remedial training for children with specific disabilities in reading, writing and penmanship. Cambridge: Educators Publishing.

Hiskes, D. G. (2011). Phonics pathways: Clear steps to easy reading and perfect spelling. San Francisco: Jossey-Bass. International Dyslexia Association. (2016). Multisensory structured language teaching. Retrieved from https://dyslexiaida.org/multisensory-structured-language-teaching/

Kormos. J., \& Smith, A. M. (2012). Teaching languages to students with specific learning differences. Bristol: Multilingual Matters. doi:10.21832/9781847696212

Kovacikova, E. (2016). Brain gym exercises in English lessons. In B. Horvathova (Ed.), Teaching together, learning together (pp. 60-64). Nitra: UKF. 
Kralova, Z., Soradova, D., \& Birova, J. (2018). Phonics generalizations in teaching foreign language pronunciation. Novosibirsk State Pedagogical University Bulletin, 8(4), 46-54. doi:10.15293/2226-3365.1804.03

Kralova, Z., Nemcokova, K., \& Birova, J. (2020). Contrastive vs non-contrastive meta-phonetic input in teaching foreign language pronunciation. Lidil. Revue de linguistique et de didactique des langues, 61, 1-12. doi: 10.4000/lidil.7377

Linguistic Phonics: Suggested line of progression and word bank for primary schools. (2009). Belfast: Southern Eastern Education and Library Board. Retrieved from http://www.belb.org.uk/Parents/literacy_linguistic.asp?sm=37

McArthur, G., Eve, P. M., Jones, K., Banales, E., Kohnen, S., Anadakumar, T., Larsen, L., Marinus, E., Wang, H. C., \& Castles, A. (2012). Phonics training for English-speaking poor readers. Cochrane Database of Systematic Reviews. Retrieved from https://www.ncbi.nlm.nih.gov/pmc/articles/PMC6517252/

McArthur, G., Kohnen, S., Jones, K., Eve, P., Banales, E., Larsen, L., \& Castles, A. (2015). Replicability of sight word training and Phonics training in poor readers: A randomised controlled trial, http://doi.org/10.7717/peerj.922

Nuttal, C. (1996). Teaching reading skills in a foreign language. London: Heinemann.

Reading rockets. (n.d.). Retrieved from http://www.readingrockets.org/teaching/reading-basics/phonics Scott, W. A., \& Ytreberg L. H. (1994). Teaching English to children: Longman keys to language learning. England: Longman.

Learning Village. Synthetic versus Analytical Phonics: Which is best for my students? (2016). Retrieved from https://www.learningvillage.net/node/1790

Wilson language training. (2016). Retrieved from http://www.wilsonlanguage.com/programs/wilson-reading-system/ 